\title{
BMJ Open Risk factors for cardiovascular disease in rural South India: cohort study
}

\author{
Prabhdeep Kaur (1) , ${ }^{1}$ Sudha Ramachandra Rao, ${ }^{1}$ Ramachandran Venkatachalam, ${ }^{1}$ \\ Boopathi Kangusamy, ${ }^{2}$ Ezhil Radhakrishnan, ${ }^{1}$ Kanagasabai Kaliaperumal, ${ }^{3}$ \\ Venkatarao Thota, ${ }^{1}$ Mohan D Gupte ${ }^{4}$
}

To cite: Kaur P, Ramachandra Rao S, Venkatachalam R, et al. Risk factors for cardiovascular disease in rural South India: cohort study. BMJ Open 2019;9:e029759. doi:10.1136/ bmjopen-2019-029759

- Prepublication history for this paper is available online. To view these files, please visit the journal online (http://dx.doi. org/10.1136/bmjopen-2019029759).

Received 10 February 2019 Revised 13 September 2019 Accepted 16 September 2019

Check for updates

(C) Author(s) (or their employer(s)) 2019. Re-use permitted under CC BY-NC. No commercial re-use. See rights and permissions. Published by BMJ.

${ }^{1}$ Division of Noncommunicable Diseases, ICMR-National Institute of Epidemiology, Chennai, India

${ }^{2}$ Division of Heath Systems Research, ICMR-National Institute of Epidemiology, Chennai, India

${ }^{3}$ Division of Computing and Information Science, ICMR-National Institute of Epidemiology, Chennai, India

${ }^{4}$ Former Director, ICMR-National Institute of Epidemiology, Chennai, India

Correspondence to Dr Prabhdeep Kaur; kprabhdeep@gmail.com

\section{ABSTRACT}

Background and objectives Cardiovascular diseases (CVD) accounted for one-third of the deaths in India. We conducted a cohort study to estimate the incidence of CVD and the association of established risk factors with the incident CVD in a rural population in South India.

Design, setting and participants We conducted a community-based cohort study among 6026 adults aged 25-64 years in five villages in Tiruvallur, Tamil Nadu. We did baseline (2005-2007) and two follow-up surveys in 2008-2009 and 2013-2015. Risk factors studied were tobacco, alcohol, hypertension, self-reported diabetes and central obesity.

Outcome measures Outcome measures were fatal or non-fatal ischaemic heart disease or cerebrovascular event. We estimated HRs for the risk factors and population attributable fraction (PAF).

Results We followed up 5641 (94.4\%) subjects, and follow-up duration was 33371 person years. The overall incidence of cardiovascular event or death was 4.6 per 1000 person years. Current smoking (HR 1.6, 95\% Cl 1.1 to 2.6) and hypertension ( $\mathrm{HR} 2.2,95 \% \mathrm{Cl} 1.5$ to 3.4 ) were the risk factors among men and accounted for $47 \%$ of the PAF. Among women, hypertension (HR $1.8,95 \% \mathrm{Cl} 1.0$ to 3.4), self-reported diabetes ( $\mathrm{HR} 4.3,95 \% \mathrm{Cl} 2.2$ to 8.1 ) and central obesity (HR 2.2, 95\% $\mathrm{Cl} 1.2$ to 4.0 ) were associated with CVD and accounted for more than half of the PAF. Conclusions We described the high burden of fatal CVD and identified the role of CVD risk factors such as hypertension, self-reported diabetes, smoking and central obesity. There is an urgent need to implement low-cost interventions such as smoking cessation and treat hypertension and diabetes in primary care settings.

\section{INTRODUCTION}

Globally, cardiovascular disease (CVD) are the leading cause of death. Although there was a decline in the CVD mortality between 1990 and 2015 in most of the high-income and middle-income countries, trend was not similar in low-income countries. ${ }^{1}$ CVD mortality among the South Asian population (369/100 000) was higher than the global average $(286 / 100000)$ in $2015 .{ }^{1}$ Since there are many risk factors for CVD, it is challenging for policy-makers and public health planners to achieve progress across all the risk factors. Reduction in cardiovascular

\section{Strengths and limitations of this study}

- Our study is one of the few cohort studies on cardiovascular risk factors in a rural population in South India.

- We had a high response rate and uniform tools for data collection for all the visits.

- Behavioural risk factors namely diet and physical activity were not included in any of the surveys.

- Diabetes was self-reported and fasting glucose or glycated hemoglobin $(\mathrm{HbA1c})$ could not be done to confirm diabetes.

- Cardiovascular disease events were recorded based on clinical records or prescription; however, we might have missed the CVD diagnosis for patients who did not have any records or did not report any treatment.

mortality would require prioritisation of risk factors in the context of the locally available data. High systolic blood pressure (BP) and smoking were the leading risk factors contributing to disability adjusted life years (DALYs) in 2016. ${ }^{2}$ A multisite case-control study with participants from 52 countries established the role of nine risk factors such as smoking, abdominal obesity, self-reported diabetes and hypertension which accounted for $90 \%$ of the population attributable risk (PAR) among men and $94 \%$ among women. ${ }^{3}$

CVD accounted for $28 \%$ of the deaths in India. ${ }^{4}$ Ischaemic heart disease was ranked sixth in terms of DALY in 1990; however, it became the leading cause in 2016. Similarly, DALY due to stroke rose from 12th place to 5th place from 1990 to $2016 .{ }^{4}$ High systolic BP was the fourth leading risk factor contributing to DALY in India in $2016 .{ }^{5}$ Although there is ample data on the burden of risk factors such as hypertension in the Indian population, there are few cohort studies which explored the relationship between the risk factors such as hypertension and CVD among Indians. ${ }^{67}$

Tamil Nadu is one of the southern states in India at an advanced level of epidemiological transition. CVDs accounted for $40 \%$ 
of the deaths among adults over 40 years in 2016. Ischaemic heart disease was the leading cause of years of life lost due to premature mortality in Tamil Nadu in $2016 .{ }^{45}$ There is ample evidence regarding the high burden of noncommunicable disease (NCD) risk factors in the rural Tamil Nadu; however, there are limited data from longitudinal studies regarding CVD incidence and risk factors. ${ }^{7}$ We had earlier reported a high prevalence of obesity, smoking and hypertension in a rural population in Tiruvallur district, Tamil Nadu. ${ }^{8}{ }^{9}$ We conducted a cohort study in the same community to estimate the incidence of CVD and the association of established risk factors with the incident CVD in a rural South India.

\section{METHODS}

\section{Study design and setting}

Tamil Nadu is one of the southern states in India with good health infrastructure and favourable health indicators. We conducted a community-based cohort study in five villages in district Tiruvallur, Tamil Nadu. All adults aged 25-64 years were considered eligible for the study at the baseline as per WHO STEPwise approach to Surveillance (STEPS) guidelines. ${ }^{10}$ We purposely selected the villages considering the access and feasibility of long-term follow-up. We collected data at baseline (2005-2007) and did two follow-up surveys in 2008-2009 and 2013-2015.

\section{Sample size}

We surveyed all eligible adults in the age group of 25-64 years at the baseline in the five villages. As we did not calculate the sample size for various risk factors at the baseline, we did power calculation to estimate if the sample size was adequate to analyse CVD outcomes for the risk factors separately among men and women. We used the input data of disease incidence among the individuals exposed to specific risk factors. The sample size was adequate, as the power for smoking, hypertension, self-reported diabetes and current alcohol consumption was $99 \%, 100 \%, 58 \%$ and $74 \%$, respectively, for men. Similarly, the power was $100 \%$ for women for all the three risk factors, namely hypertension, self-reported diabetes and central obesity.

\section{Risk factors}

We collected data for risk factors such as age, education, tobacco use, alcohol consumption, self-reported hypertension and self-reported diabetes using a structured questionnaire.

Tobacco use: current smoker was defined as a person who had smoked at least 100 cigarettes over his/her lifetime and continued to smoke at the time of survey daily or occasionally. An ex-smoker was the one who had quit smoking. ${ }^{11}$ Current smokeless tobacco use was defined as the daily of occasional use of any form of smokeless tobacco at the time of the survey.

Current alcohol consumption: current consumer was defined as the consumption of alcohol in the previous
12 months. The past consumer was alcohol consumption before the previous 12 months. ${ }^{12}$

Hypertension: we measured the $\mathrm{BP}$ in the right arm after sitting for at least 5 min using a digital automatic BP apparatus (Omron MX3) as recommended in WHO STEPS manual. ${ }^{10}$ We recorded the average of the two readings taken 5 min apart. The definition of hypertension at baseline survey was systolic $\mathrm{BP} \geq 140 \mathrm{~mm} \mathrm{Hg}$ or diastolic $\mathrm{BP} \geq 90 \mathrm{~mm} \mathrm{Hg}$ as per WHO criteria or history of the previously diagnosed disease. ${ }^{13}$

Central obesity: we measured waist circumference (WC) to the nearest $0.1 \mathrm{~cm}$ at the narrowest point between the lower end of the rib cage and iliac crest. Field investigators were trained to do WC as per the standard protocol. Privacy was maintained for female respondents while doing WC measurements. Female investigators did the measurements inside the house for female respondents during the door-to-door survey. We defined central obesity as WC $\geq 90 \mathrm{~cm}$ for men and $\mathrm{WC} \geq 80 \mathrm{~cm}$ for women. ${ }^{14}$

\section{Outcome measures}

Incident CVD was the occurrence of fatal or non-fatal ischaemic heart disease, acute myocardial infarction or cerebrovascular event. We reviewed the clinical records, hospital discharge summaries and prescriptions to establish the diagnosis of ischaemic heart disease or cerebrovascular disease. As the study villages were approximately 30-50 km from a major metropolitan city, Chennai; most patients sought care in the tertiary care facilities in Chennai. The area has a primary healthcare centre, which provides treatment for hypertension and diabetes; however, CVD cases are referred to tertiary care hospitals in Chennai.

We also examined the death certificate, if available. We conducted verbal autopsy using a validated tool for all the deaths in the cohort during follow-up visits. ${ }^{15}$ The tool includes questions regarding various symptoms, history of pre-existing diseases, prior treatment history and detailed narrative section. We classified the events and deaths in International Classification of Diseases. We defined CVD according to the ICD codes I20-I25 (ischaemic heart disease) and I60-I69 (cerebrovascular disease). ${ }^{16} \mathrm{We}$ referred patients with newly detected hypertension to the closest primary health centre for further management. We referred the patients with diagnosed ischaemic heart disease or stroke to the nearest tertiary care health facility.

\section{Statistical analysis}

The outcome measure was the first event of CVD or CVD death. The overall incidence of CVD per 1000 person years was computed. Person time defined as the date of the baseline survey to either date of last survey or date of death. Cox proportional hazards regression model was done for each risk factor independently in model 1 and adjusted for baseline age as a continuous variable in model 2. In model 3, we included all the risk factors in addition to age as a continuous variable and interactions. 
We calculated HRs with $95 \% \mathrm{CI}$, and $\mathrm{p}$ values for each of the risk factors.

We computed population attributable fraction (PAF) with $95 \%$ CIs for various risk factors individually and cumulatively based on the adjusted HR. ${ }^{17} \mathrm{PAF}$ is the fraction of disease risk which can be potentially eliminated from the population if the risk factor is removed. All analyses were performed using Stata, V.13.0. ${ }^{18}$

\section{Patient and public involvement}

We did the surveys in the field practice area of our institution in Tiruvallur district. While doing surveys for various infectious diseases, community members informed the field staff about many deaths due to heart attacks and lack of adequate health facilities to seek treatment. We discussed with the community regarding their willingness to participate in the research involving repeat surveys for cardiovascular risk factors and received positive feedback. We counselled the patients with hypertension, diabetes and CVD for lifestyle modification and treatment during the surveys. We shared the information about the high burden of untreated hypertension and other risk factors with the community members and local health authorities after completing the surveys. Government of Tamil Nadu has strengthened the rural public sector health facilities catering to the study population in terms of services and drugs for hypertension and diabetes over the past decade.

\section{RESULTS}

At baseline, we surveyed 6026 (90.8\%) subjects among 6639 eligible adults aged 25-64 years in the study villages. The reasons for non-response were absence after three visits $(597(9.0 \%))$, pregnancy $(6(0.09 \%))$, refusal (3 $(0.05 \%))$ and physically handicapped $(7(0.1 \%))$ We excluded 48 subjects who reported CVD at the baseline and followed up the remaining study participants. Among 5978 subjects in the cohort, we followed up 5641 (94.4\%) subjects during two follow-up visits. The primary reason for loss to follow-up was migration from the study villages. Total follow-up duration was 33371 person years, and the median duration of follow-up was 7 years. There was a total of 96 deaths (79 ischaemic heart disease and 17 cerebrovascular disease) and 58 events (46 ischaemic heart disease and 12 cerebrovascular disease) due to CVD. The overall incidence of CVD event or death was 4.6 per 1000 person years. Among them, the incidence of CVD death was 2.9 per 1000 person years, and CVD event was 1.7 per 1000 person years. Overall incidence was higher among men as compared with women (7.2 vs 2.7 per 1000 person years).

We surveyed 2570 men and 3071 women at the baseline. The baseline characteristics of the participants with and without CVD are presented in tables 1 and 2. Overall, $66.6 \%$ of the study participants were below 45 years. Among men, $36.6 \%$ had $\leq 5$ years of school education, $34.9 \%$ were smokers, $28.6 \%$ were alcohol user and $20.2 \%$ were centrally obese. Among women, $66.5 \%$ had $\leq 5$ years of school education, $59.2 \%$ did not engage in any paid work, $43 \%$ were smokeless tobacco users and $26.4 \%$ were centrally obese. Hypertension was prevalent in one-fifth $(21.6 \%)$ of the men and women, and $4.0 \%$ had self-reported diabetes (tables 1 and 2).

We estimated the unadjusted HR for education, occupation, smoking, current alcohol consumption, hypertension, self-reported diabetes and central obesity among men. Lack of school education or less than 6 years of school education and farmer/manual labour were associated with CVD; however, it was not significant after adjusting for age. Current smoking was associated with a 1.6-fold increased risk of CVD after adjusting for all other risk factors. Current alcohol consumption was associated with 1.7-fold increased risk in model 2; however, HR (1.3, 95\% CI 0.9 to 2.0) was not significant after adjusting for other risk factors. There was a twofold increased risk of the disease due to hypertension in model 3 (HR 2.2, 95\% CI 1.5 to 3.4). Self-reported diabetes and central obesity were not significantly associated with the outcome after adjusting for age. We also examined the interaction effect of central obesity and hypertension/diabetes for CVD. The interaction effect was not statistically significant. Among men, hypertension (24.0\%) and smoking (23.4\%) had high PAF (table 3).

We estimated the unadjusted HR for education, occupation, smokeless tobacco use, hypertension, self-reported diabetes and central obesity among women. The level of education and lack of paid work were not associated with CVD. The HR for hypertension was 1.8 (95\% CI 1.0 to 3.4) after adjusting for all risk factors. The HR adjusted for age and all other risk factors for self-reported diabetes and obesity was 4.3 (95\% CI 2.2 to 8.1 ) and 2.2 (95\% CI 1.2 to 4.0 ), respectively. Similar to men, there was no interaction effect of central obesity and hypertension/diabetes for CVD. The major risk factors accounted for $69 \%$ of the disease (table 4 ).

\section{DISCUSSION}

We examined the role of various cardiovascular risk factors in a rural cohort in South India. Our study had a high response rate, uniform tools for data collection in all the visits and the same team of interviewers throughout the study, which ensured high quality of data and good rapport with the community. Although there are sufficient data regarding the high NCD risk factor burden in South India, there are only two longitudinal studies from urban India which documented the role of established risk factors such as hypertension in causing CVD ${ }^{67}$ Our research is unique as it documented the CVD incidence and role of risk factors in the context of epidemiological transition in the rural population in the previous decade.

One of the critical observation was that nearly two-thirds of the CVD events were fatal in the study population. A multisite prospective urban rural epidemiology (PURE) cohort study reported high fatality among patients with CVD in low-income (six times) and middle income 
Table 1 Person years of follow-up and proportion with and without cardiovascular disease (CVD) in the risk factors categories among men, Tiruvallur, India

\begin{tabular}{|c|c|c|c|c|c|}
\hline \multirow[b]{2}{*}{ Risk factors } & \multirow{2}{*}{$\begin{array}{l}\text { Follow-up duration (total }-14 \\
510 \text { person years) }\end{array}$} & \multicolumn{2}{|c|}{ CVD (n=104) } & \multicolumn{2}{|c|}{ No CVD $(n=2466)$} \\
\hline & & $\mathbf{n}$ & $\%$ & n & $\%$ \\
\hline \multicolumn{6}{|l|}{ Age group (years) } \\
\hline $25-34$ & 5288.5 & 12 & 11.5 & 905 & 36.7 \\
\hline $35-44$ & 4545.5 & 26 & 25.0 & 769 & 31.2 \\
\hline $45-54$ & 3259.0 & 34 & 32.7 & 547 & 22.2 \\
\hline $55-64$ & 1417.0 & 32 & 30.8 & 245 & 9.9 \\
\hline \multicolumn{6}{|l|}{ Education } \\
\hline Not attended school & 1785.0 & 22 & 21.2 & 299 & 12.1 \\
\hline $1-5$ years of school education & 3407.5 & 35 & 33.7 & 585 & 23.7 \\
\hline $6-8$ years of school education & 3269.5 & 19 & 18.3 & 552 & 22.4 \\
\hline $\begin{array}{l}9-12 \text { years of school education and } \\
\text { above }\end{array}$ & 6048.0 & 28 & 26.9 & 1030 & 41.8 \\
\hline \multicolumn{6}{|l|}{ Occupation } \\
\hline Farmer owns land & 907.5 & 14 & 13.5 & 134 & 5.4 \\
\hline Labourer & 8140.5 & 61 & 58.7 & 1393 & 56.5 \\
\hline Salaried employee/self-employed & 5462.0 & 29 & 27.9 & 939 & 38.1 \\
\hline \multicolumn{6}{|l|}{ Smoking } \\
\hline Non-smoker & 9589.0 & 48 & 46.2 & 1624 & 65.9 \\
\hline Current smoker & 4921.0 & 56 & 53.8 & 842 & 34.1 \\
\hline \multicolumn{6}{|l|}{ Alcohol consumption } \\
\hline No & 10471.5 & 62 & 59.6 & 1774 & 71.9 \\
\hline Yes & 4038.5 & 42 & 40.4 & 692 & 28.1 \\
\hline \multicolumn{6}{|l|}{ Hypertension } \\
\hline Present & 3051.0 & 47 & 45.2 & 509 & 20.6 \\
\hline Absent & 11459.0 & 57 & 54.8 & 1957 & 79.4 \\
\hline \multicolumn{6}{|l|}{ Diabetes (self-reported) } \\
\hline Present & 552.5 & 9 & 8.7 & 95 & 3.9 \\
\hline Absent & 13957.5 & 95 & 91.3 & 2371 & 96.1 \\
\hline \multicolumn{6}{|l|}{ Central obesity } \\
\hline Obese & 2924.0 & 26 & 25.0 & 493 & 20.0 \\
\hline Normal & 11586.0 & 78 & 75.0 & 1973 & 80.0 \\
\hline
\end{tabular}

(three times) countries as compared with high-income countries. ${ }^{19}$ High fatality in the context of the scarce resource as observed in our study setting might be due to a combination of lack of control of the risk factors and lack of access to timely emergency care. A global monitoring framework has been adopted to monitor the implementation of interventions for NCD, including CVD. The primary outcome indicator is a $25 \%$ relative reduction in the premature mortality from NCD (CVDs, cancer, diabetes or chronic respiratory diseases).$^{20} \mathrm{~A}$ multipronged strategy with a combination of community-based interventions targeting the risk behaviours and health systems strengthening might improve the treatment coverage and reduce the CVD burden in India. Our study reinforced the importance of modifiable risk factors in the context of high CVD burden in India. In a subgroup analysis of a case-control INTERHEART study, among South Asians, four risk factors namely hypertension $(19.3 \%)$, self-reported diabetes (11.8\%), smoking $(37.5 \%)$ and central obesity $(37.7 \%)$ were associated with high PAR for myocardial infarction. ${ }^{21}$ We observed a similar pattern for hypertension and smoking. Central obesity and self-reported diabetes were related to high PAR only among women in our cohort. We can nearly prevent half of the CVD by reducing the burden of these modifiable risk factors in the study population.

Hypertension emerged as one of the significant risk factors for CVD in the rural population in South India. Mumbai cohort study demonstrated that hypertension nearly doubled the risk of circulatory system deaths in 
Table 2 Person years of follow-up and proportion with and without cardiovascular disease (CVD) in the risk factors categories among women, Tiruvallur, India

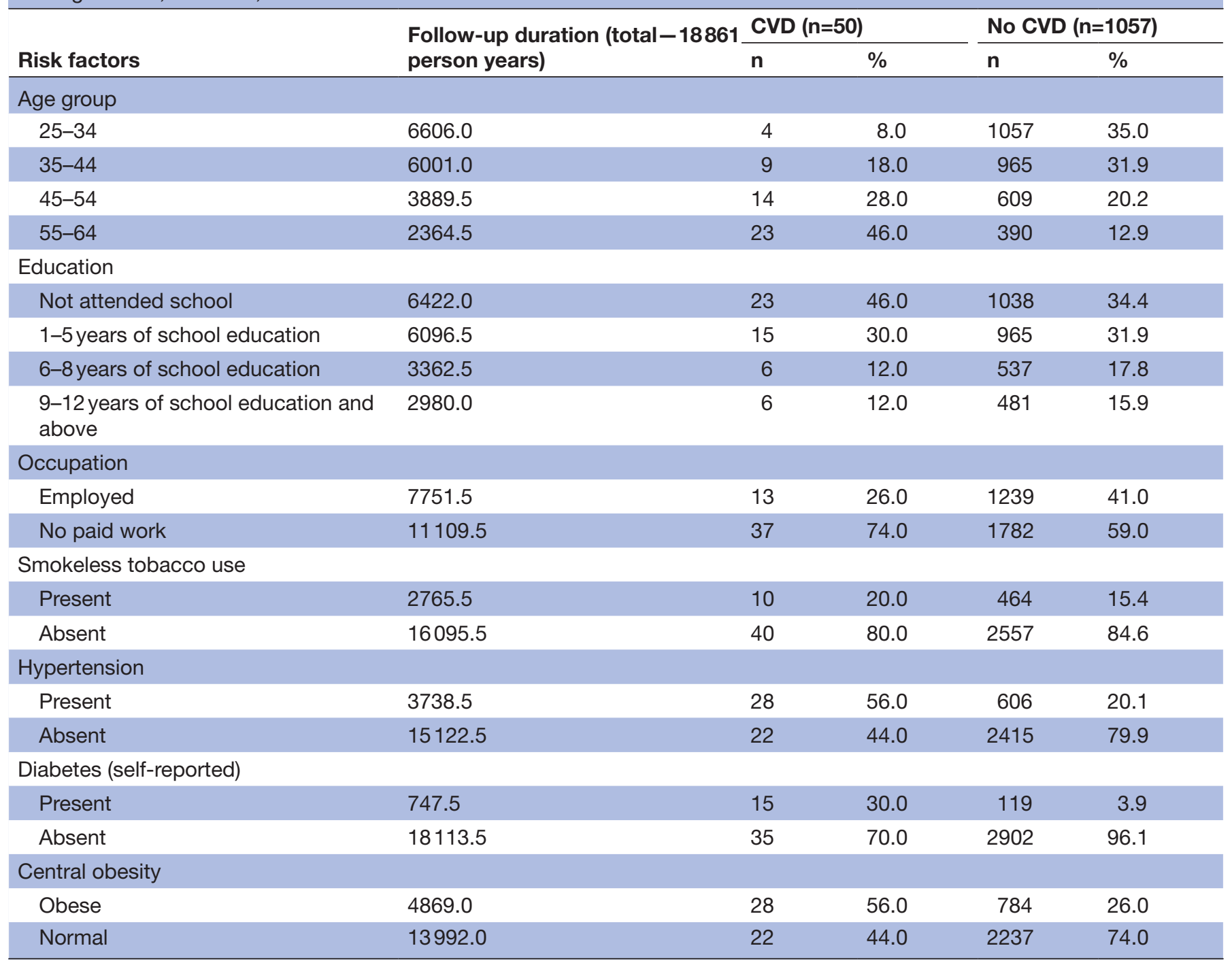

an urban community. ${ }^{6}$ A cohort study from Chennai-a large metropolitan in Tamil Nadu-reported that an increase of $20 \mathrm{~mm} \mathrm{Hg}$ systolic BP was associated with a relative risk of 2.45 and 1.74 for stroke and cardiac mortality, respectively. ${ }^{7}$

Our study reiterates the importance of hypertension management and control for the urban and for the rural populations. Combination of high prevalence $(21.4 \%$ ) and poor control $(6.6 \%)$ in the study population was already reported in 2006. ${ }^{9}$ Poor hypertension control might have been one of the primary reason for cardiovascular events in our cohort. Hypertension is a high priority risk factor in the context of India, which is home to 200 million adults with raised BP among nearly a billion adults with elevated BP globally. Mean systolic BP of South Asian population, including India, showed an upward trend over the past decades, unlike high-income western countries. $^{22}$ The rising trend is contrary to the goal of $25 \%$ relative reduction of raised $\mathrm{BP}$ by $2025 .^{20}$ There is ample evidence regarding the efficacy of $\mathrm{BP}$ control in reducing
CVD mortality. A global perspective studies collaboration involving a million participants estimated a $50 \%$ reduction in coronary heart disease (CHD) mortality for 20 $\mathrm{mm} \mathrm{Hg}$ decline in the systolic BP across 40-69 years of age. ${ }^{23}$ The treatment of raised $\mathrm{BP}$ with low-cost affordable drugs is one of the cost-effective intervention for low-resource settings and should be scaled up rapidly to reduce CVD mortality. ${ }^{24}$

Smoking was one of the main risk factors for CVD among men in our study. A pooled analysis of 40 cohort studies from the Asia Pacific region concluded that smoking was a risk factor for CHD and stroke. The risk of CHD was 1.6-fold and haemorrhagic stroke 1.2-fold among smokers as compared with non-smokers, risk being higher among the population from Australia/New Zealand as compared with Asians. ${ }^{25}$ Among South Asians in INTERHEART case-control study, smoking was associated with nearly 2.5-fold increased odds of myocardial infarction. ${ }^{21}$ Given the available evidence, smoking should continue to be a priority area for public health interventions to reduce the 
Table 3 Cardiovascular disease risk factors and population attributable fraction (PAF) for various risk factors among men, Tiruvallur, India

\begin{tabular}{|c|c|c|c|c|}
\hline & HR $(95 \% \mathrm{Cl})$ & HR $(95 \% \mathrm{Cl})$ & HR $(95 \% \mathrm{Cl})$ & $\operatorname{PAF}(95 \% \mathrm{Cl})$ \\
\hline Factors & Unadjusted & Age adjusted & All adjusted & (\%) \\
\hline \multicolumn{5}{|l|}{ Age group } \\
\hline 25-34 & 1 & & & \\
\hline $35-44$ & 2.519 (1.3 to 5.0$)$ & & & \\
\hline $45-54$ & 4.576 (2.4 to 8.8$)$ & & & \\
\hline $55-64$ & 9.871 (5.1 to 19.2$)$ & & & \\
\hline \multicolumn{5}{|l|}{ Education } \\
\hline Not attended school & 2.656 (1.5 to 4.6$)$ & 1.407 (0.8 to 2.5$)$ & $1.257(0.7$ to 2.3$)$ & \\
\hline 5 years of schooling & 2.211 (1.3 to 3.6$)$ & 1.384 (0.8 to 2.3$)$ & 1.281 (0.7 to 2.2$)$ & \\
\hline 8 years of schooling & 1.255 (0.7 to 2.2$)$ & 1.014 (0.6 to 1.8$)$ & 0.897 (0.5 to 1.6$)$ & \\
\hline 12 years of schooling and above & 1 & & & \\
\hline \multicolumn{5}{|l|}{ Occupation } \\
\hline Farmer owns land & 2.894 (1.5 to 5.5$)$ & 1.465 (0.8 to 2.8$)$ & 1.652 (0.9 to 3.2$)$ & 0.0 (0.0 to 23.1$)$ \\
\hline Labourer & 1.407 (0.9 to 2.2$)$ & 0.932 (0.6 to 1.5$)$ & 0.833 (0.5 to 1.4$)$ & \\
\hline Salaried employee/self employed & 1 & & & \\
\hline \multicolumn{5}{|l|}{ Smoking } \\
\hline Non-smoker & 1 & & & \\
\hline Current smoker & 2.266 (1.5 to 3.3$)$ & $1.718(1.2$ to 2.5$)$ & $1.672(1.1$ to 2.6$)$ & 23.4 (4.3 to 38.6$)$ \\
\hline \multicolumn{5}{|l|}{ Alcohol consumption } \\
\hline No & 1 & & & \\
\hline Yes & 1.755 (1.2 to 2.6$)$ & 1.686 (1.1 to 2.5$)$ & $1.300(0.9$ to 2.0$)$ & 9.7 (0.0 to 23.9$)$ \\
\hline \multicolumn{5}{|l|}{ Hypertension } \\
\hline Absent & 1 & & & \\
\hline Present & 3.092 (2.1 to 4.6$)$ & 2.249 (1.5 to 3.3$)$ & $2.272(1.5$ to 3.4$)$ & 24.2 (9.6 to 36.4 ) \\
\hline \multicolumn{5}{|l|}{ Diabetes (self-reported) } \\
\hline Absent & 1 & & & \\
\hline Present & $2.383(1.2$ to 4.7$)$ & 1.296 (0.6 to 2.6$)$ & 1.243 (0.6 to 2.6$)$ & $2.0(0.0$ to 7.9$)$ \\
\hline \multicolumn{5}{|l|}{ Central obesity } \\
\hline Normal & 1 & & & \\
\hline Obese & $1.316(0.8$ to 2.1$)$ & 1.164 (0.7 to 1.8$)$ & 1.009 (0.6 to 1.7$)$ & $1.3(0$ to 13.3$)$ \\
\hline Cumulative PAF & & & & $45.4(12.6$ to 66.0$)$ \\
\hline
\end{tabular}

CVD burden among men. Although there was a decline in the age-standardised prevalence of smoking among men 15-69 years from $27 \%$ (1998) to $24 \%$ (2010) over a decade in India, there was an increase in the smoking prevalence among men 15-29 years during this period and proportion who quit smoking was low. ${ }^{26}$ Combination of policy interventions such as high taxation and access to smoking cessation services might increase the smoking cessation rates in the future.

Central obesity is the more crucial anthropometric measure for myocardial infarction as compared with body mass index, more so among South Asians. ${ }^{321}$ There is ample evidence of the high prevalence of central obesity and diabetes among the South Indian population. In rural Tamil Nadu, the prevalence of central obesity and diabetes was $22.1 \%$ and $7.8 \%$, respectively. ${ }^{27}{ }^{28}$ Besides, a case-control study from Bangalore, South India, documented the association of central obesity and diabetes with acute myocardial infarction in South Indians. ${ }^{29}$ Our study reiterated the importance of central obesity and diabetes for CVD, especially among women in a longitudinal cohort.

The study had several limitations. We did purposive sampling for selection of villages from the institution's field practice area considering access and travel time to reach the villages, which could cause selection bias. The 
Table 4 Cardiovascular disease risk factors and population attributable fraction (PAF) for various risk factors among women, Tiruvallur, India

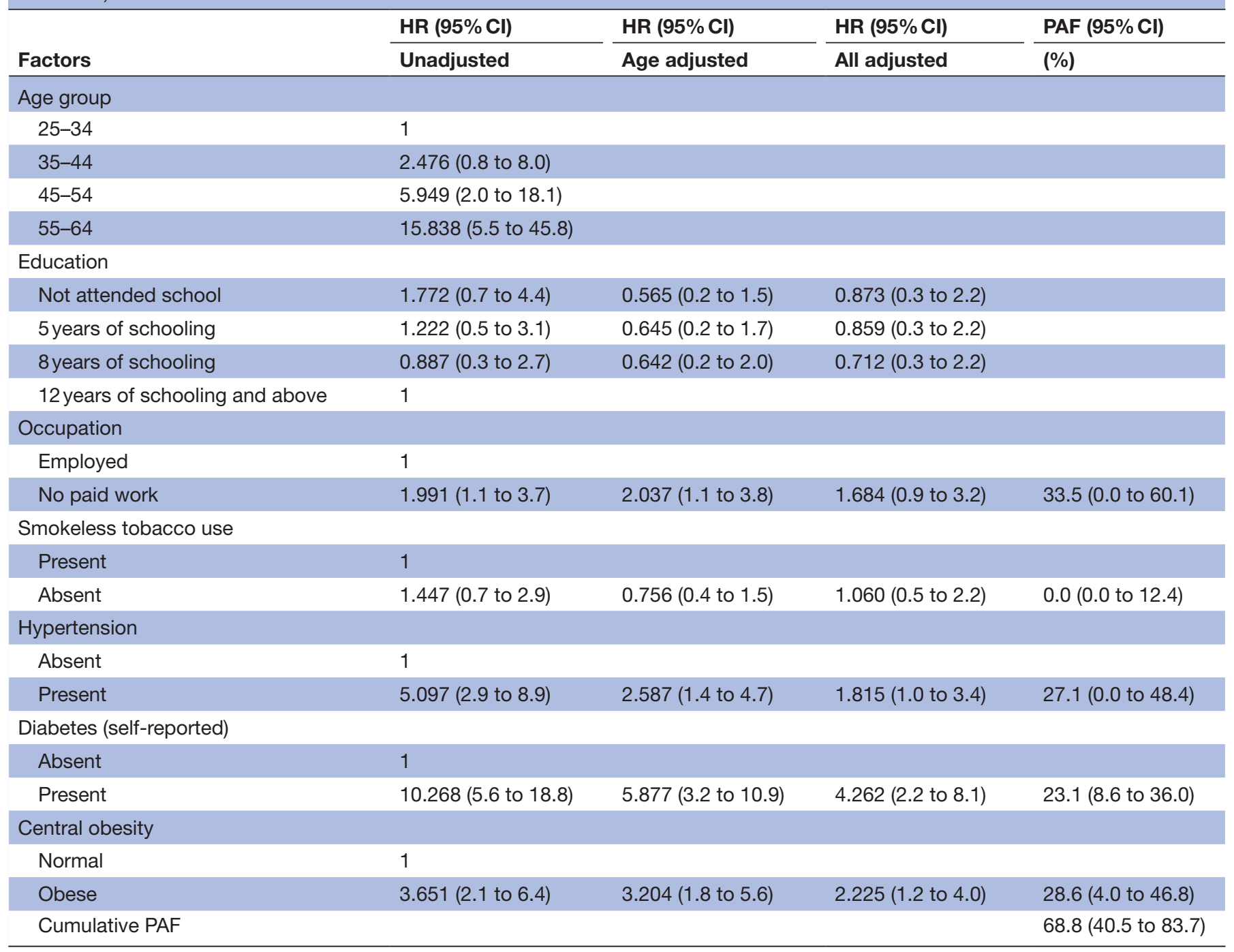

study population was similar to the rural population of the district as per age distribution, sex ratio and literacy. ${ }^{30}$ The diabetes was self-reported and fasting glucose or HbA1c could not be done to confirm diabetes. Therefore, we might have underestimated the burden of diabetes in the population. We did not collect data regarding diet, physical inactivity and serum cholesterol and cannot comment regarding the role of these risk factors. BP was measured twice only during one visit, which could have led to an overestimation of the burden of hypertension. CVD events were recorded based on clinical records or prescription; however, we might have missed the CVD diagnosis for patients who did not have any records or did not report any treatment.

Indian states are at varying levels of the epidemiological transition and therefore have a variable burden of NCDs. Tamil Nadu is already in the advanced stage of epidemiological transition with the high burden of NCD risk factors in the urban and in the rural areas. ${ }^{5}$

We observed the high burden of fatal CVD and confirmed the role of established risk factors such as hypertension, diabetes, smoking and central obesity for CVD. The findings indicate the need for a shift in the policy and programme to address NCD control while sustaining the gains made in infectious disease control. Although there have been efforts to improve NCD care in the state in the past few years, there should be a sustained investment for the implementation of low-cost interventions such as smoking cessation and treatment of risk factors in the primary care. Health systems need to be strengthened to achieve high coverage of treatment of hypertension and diabetes in the rural population to reduce the CVD morbidity and mortality.

Acknowledgements The authors thank community members for their time and support in various surveys. They thank field team leader Kirubanithy and all field investigators for ensuring high coverage and good quality data collection during surveys. They thank the administrative staff of ICMR-NIE for supporting all the project activities.

Contributors PK designed the study, supervised fieldwork, planned data analysis and wrote the first draft of the paper. SRR, RV and BK supervised data collection for quality, analysed the data and revised the manuscript. ER and KK designed the data collection tools, managed data and gave critical comments in finalising the 
manuscript. VT and MDG conceptualised the study and gave critical comments in finalising the manuscript. All authors approved the final manuscript.

Funding This work was supported by ICMR-National Institute of ChennaiIntramural funds.

Competing interests None declared.

Patient consent for publication Not required.

Ethics approval Institutional Ethics Committee of ICMR-National Institute of Epidemiology, Chennai, approved the study. Written consent was obtained from all participants.

Provenance and peer review Not commissioned; externally peer reviewed.

Data availability statement Data are available upon reasonable request.

Open access This is an open access article distributed in accordance with the Creative Commons Attribution Non Commercial (CC BY-NC 4.0) license, which permits others to distribute, remix, adapt, build upon this work non-commercially, and license their derivative works on different terms, provided the original work is properly cited, appropriate credit is given, any changes made indicated, and the use is non-commercial. See: http://creativecommons.org/licenses/by-nc/4.0/.

\section{ORCID iD}

Prabhdeep Kaur http://orcid.org/0000-0002-2605-3739

\section{REFERENCES}

1 Roth GA, Johnson C, Abajobir A, et al. Global, regional, and national burden of cardiovascular diseases for 10 causes, 1990 to 2015. J Am Coll Cardiol 2017;70:1-25.

2 Gakidou E, Afshin A, Abajobir AA, et al. Global, regional, and national comparative risk assessment of 84 behavioural, environmental and occupational, and metabolic risks or clusters of risks, 1990-2016: a systematic analysis for the global burden of disease study 2016 . The Lancet 2017;390:1345-422.

3 Yusuf S, Hawken S, Ônpuu S, et al. Effect of potentially modifiable risk factors associated with myocardial infarction in 52 countries (the INTERHEART study): case-control study. The Lancet 2004;364:937-52.

4 Dandona L, Dandona R, Kumar GA, et al. Nations within a nation: variations in epidemiological transition across the states of India, 1990-2016 in the global burden of disease study. The Lancet 2017;390:2437-60.

5 Indian Council of Medical research PHFOI, and Institute of Health Metrics and Evaluation India: Health of the Nation's States - The India State-level Disease Burden Initiative New Delhi: ICMR, PHFI and IHME, 2017. Available: http://www.healthdata.org/sites/default/ files/files/policy_report/2017/India_Health_of_the_Nation\%27s_ States Report 2017.pdf [Accessed 29 Aug 2018].

6 Pednekar MS, Gupta R, Gupta PC. Association of blood pressure and cardiovascular mortality in India: Mumbai cohort study. Am J Hypertens 2009;22:1076-84.

7 Gajalakshmi V, Lacey B, Kanimozhi V, et al. Body-mass index, blood pressure, and cause-specific mortality in India: a prospective cohort study of 500810 adults. Lancet Glob Health 2018;6:e787-94.

8 Kaur P, Rao SR, Radhakrishnan E, et al. High prevalence of tobacco use, alcohol use and overweight in a rural population in Tamil Nadu, India. J Postgrad Med 2011;57:9.

9 Kaur P, Rao SR, Radhakrishnan E, et al. Prevalence, awareness, treatment, control and risk factors for hypertension in a rural population in South India. Int J Public Health 2012;57:87-94.

10 World Health Organization. Stepwise approach to surveillance (steps) 2016. Available: http://www.who.int/chp/steps/en/ [Accessed 20 Jun 2016].
11 Office on Smoking and Health NCfCDPaHP. Current cigarette smoking among adults in the United States Atlanta, USA: center for disease control and prevention, 2018. Available: https://www.cdc. gov/tobacco/data_statistics/fact_sheets/adult_data/cig_smoking/ index.htm [Accessed 27 Aug 2018].

12 National Institute of Medical Statistics ICoMR. IDSP noncommunicable disease risk factors survey, phase-I states of India, 2007-08. New Delhi, 2009

13 Whitworth JAWorld Health Organization, International Society of Hypertension Writing Group . 2003 World Health Organization (WHO)/International Society of Hypertension (ISH) statement on management of hypertension. J Hypertens 2003;21:1983-92.

14 Inoue S, Zimmet P, Caterson I, et al. The Asia-Pacific perspective: redefining obesity and its treatment. Sydney, 2000.

15 Jha P, Gajalakshmi V, Gupta PC, et al. Prospective study of one million deaths in India: rationale, design, and validation results. PLoS Med 2006;3:e18

16 ICD10Data.com. ICD10Data.com USA: ICD10Data.com, 2018. Available: https://www.icd10data.com/

17 Mansournia MA, Altman DG. Population attributable fraction. BMJ 2018;360.

18 StataCorp. Stata statistical software: release 13. College Station, tx: StataCorp Lp, 2013. Available: https://www.stata.com/support/faqs/ resources/citing-software-documentation-faqs/ [Accessed 27 Aug 2018].

19 Yusuf S, Rangarajan S, Teo K, et al. Cardiovascular risk and events in 17 low-, middle-, and high-income countries. $N$ Engl J Med 2014;371:818-27.

20 World Health Organization. Non communicable diseases global monitoring framework: indicator definitions and specifications. Geneva, 2013.

21 Joshi P, Islam S, Pais P, et al. Risk factors for early myocardial infarction in South Asians compared with individuals in other countries. JAMA 2007;297:286-94.

22 Zhou B, Bentham J, Di Cesare M, et al. Worldwide trends in blood pressure from 1975 to 2015: a pooled analysis of 1479 populationbased measurement studies with $19 \cdot 1$ million participants. The Lancet 2017;389:37-55.

23 Prospective Studies Collaboration. Age-Specific relevance of usual blood pressure to vascular mortality: a meta-analysis of individual data for one million adults in 61 prospective studies. The Lancet 2002;360:1903-13.

24 World Health Organization. Package of essential noncommunicable (Pen) disease interventions for primary health care in low-resource settings. Geneva, 2010.

25 Woodward M, Lam TH, Barzi F, et al. Smoking, quitting, and the risk of cardiovascular disease among women and men in the Asia-Pacific region. Int J Epidemiol 2005;34:1036-45.

26 Mishra S, Joseph RA, Gupta PC, et al. Trends in bidi and cigarette smoking in India from 1998 to 2015 , by age, gender and education. BMJ Glob Health 2016;1.

27 Anjana RM, Pradeepa R, Deepa M, et al. Prevalence of diabetes and prediabetes (impaired fasting glucose and/or impaired glucose tolerance) in urban and rural India: phase I results of the Indian Council of medical Research-INdia diabetes (ICMR-INDIAB) study. Diabetologia 2011;54:3022-7.

28 Pradeepa R, Anjana RM, Joshi SR, et al. Prevalence of generalized \& abdominal obesity in urban \& rural India--the ICMR-INDIAB Study (Phase-I) [ICMR- NDIAB-3]. Indian J Med Res 2015;142:139.

29 Pais P, Pogue J, Gerstein H, et al. Risk factors for acute myocardial infarction in Indians: a case-control study. The Lancet 1996;348:358-63.

30 Director Census Operations Tamil Nadu. Census of India, provisional population totals, Tamil Nadu Chennai: director census operations Tamil Nadu, 2011. Available: http://censusindia.gov.in/2011-provresults/paper2/data_files/tamilnadu/Tamil Nadu_PPT2_Volume1_ 2011.pdf 